\title{
Omeprazole was better than cisapride or placebo for controlling heartburn at 4 and 8 weeks
}

Hatlebakk JG, Hyggen A, Madsen PH, et al, on behalf of the Norwegian Heartburn Study Group. Heartburn treatment in primary care: randomised, double blind study for 8 weeks. BMJ 1999 Aug 28;319:550-3.

\section{QUESTION: In patients with heartburn, are omeprazole and cisapride effective for} controlling symptoms?

\section{Design}

8 week randomised (allocation concealed*), blinded (patients and outcome assessors),* controlled trial.

\section{Setting}

65 primary care practices in liaison with endoscopy units and pharmacies in Norway.

\section{Patients}

$\{484\} \uparrow$ patients who were 18 to 80 years of age (median age $47 \mathrm{y}$ in the cisapride group, $49 \mathrm{y}$ in the omeprazole group, $50 \mathrm{y}$ in the placebo group; $52 \%$ men) and had had heartburn for $\geq 3 \mathrm{~d} /$ wk for $\geq 3$ months during a 14 day run in period. Exclusion criteria were grade 2 or 3 oesophagitis; Barrett oesophagus; peptic ulcer disease; gallstone disease; oesophagogastric surgery; use of prokinetic, antisecretory, or antibiotic medication in the 2 weeks before endoscopy; substance abuse; need for an interpreter; or other diseases that might affect symptom assessment. Follow up was $\{96 \%\} \uparrow$ at 4 weeks and $90 \%$ at 8 weeks; all patients except 1 were included in the analysis.

\section{Intervention}

Patients were allocated to omeprazole, one $20 \mathrm{mg}$ capsule daily $(\mathrm{n}=161)$; cisapride, two $10 \mathrm{mg}$ tablets twice daily $(\mathrm{n}=163)$; or placebo $(\mathrm{n}=159)$. Calcium carbonate antacid tablets were given for use when heartburn occurred.

\section{Main outcome measures}

Adequate control of heartburn (defined as $\leq 1 \mathrm{~d}$ with no more than mild heartburn in the previous $7 \mathrm{~d}$ ). Adverse events were also assessed.

\section{Main results}

Omeprazole led to greater control of heartburn than did placebo or cisapride at $4(\mathrm{p}<0.001)$ and 8 weeks $(\mathrm{p}<0.001)$ (table). Patients who received cisapride reported more adverse events after 4 weeks than did those who received omeprazole $(\mathrm{p}=0.024)$ or placebo $(\mathrm{p}=0.004)$.

\section{Conclusion}

In patients with heartburn, omeprazole was more effective than cisapride or placebo for achieving adequate control. *See glossary.

$\uparrow$ Additional information supplied by the $B M J$ website (http://www.bmj.com).

Omeprazole (Ome), cisapride (Cis), and placebo for heartburn $\$$

\begin{tabular}{|c|c|c|c|c|c|}
\hline Outcomes & Ome & Cis & Placebo & $\mathrm{RBI}(95 \% \mathrm{Cl})$ & NNT (Cl) \\
\hline \multirow[t]{3}{*}{ Adequate heartburn control at $4 \mathrm{wk}$} & $71 \%$ & - & $18 \%$ & $288 \%(179$ to 451$)$ & $2(2$ to 3$)$ \\
\hline & $71 \%$ & $22 \%$ & - & $221 \%(139$ to 338$)$ & $3(2$ to 3$)$ \\
\hline & - & $22 \%$ & $18 \%$ & $21 \%(-21$ to 87$)$ & Not significant \\
\hline \multirow[t]{3}{*}{ Adequate heartburn control at $8 \mathrm{wk}$} & $76 \%$ & - & $30 \%$ & $151 \%$ (97 to 226$)$ & $3(2$ to 3$)$ \\
\hline & $76 \%$ & $40 \%$ & - & $90 \%(55$ to 136$)$ & $3(3$ to 4$)$ \\
\hline & - & $40 \%$ & $30 \%$ & $32 \%(-2$ to 79$)$ & Not significant \\
\hline
\end{tabular}

$\ddagger$ Abbreviations defined in glossary; RBI, NNT, and $\mathrm{Cl}$ calculated from data in article.

\section{COMMENTARY}

The study by Hatlebakk and colleagues provides evidence of estimable quality. It includes all of the elements necessary for a therapeutic trial, and the final result is an impressive vindication of the benefits of omeprazole for heartburn without complications. This does not mean, however, that all patients with heartburn should now be treated with omeprazole.

The patients in this trial may not be typical patients with heartburn. $50 \%$ had heartburn every day, and $75 \%$ reported that heartburn interfered with daily activities. They may be more typical of primary care patients because $51 \%$ had grade 1 oesophagitis only and the rest had none, although this and other studies suggest that endoscopic findings may not correlate closely with symptoms. ${ }^{1}$

The scope for non-drug measures was not tested. These measures should remain a first line strategy primarily because, if effective, the benefits are likely to be sustained. The benefits of omeprazole in this trial have only been shown to last for the 8 weeks of drug therapy. Longer term treatment may be needed to sustain benefit, and omeprazole may prove expensive if it has to be taken for a long period. Antacids or $\mathrm{H}_{2}$-blockers may be adequate for some patients. Other proton pump inhibitors may be less expensive and equally effective. An intermittent regimen might also be effective. ${ }^{2}$ The appropriate use of such inhibitors is not as simple a matter as this study might imply.

Colin P Bradley, MD

University College Cork

Cork, Ireland

1 Bate CM, Green JR, Axon AT, et al. Omeprazole is more effective than cimetidine for the relief of all grades of gastro-oesophageal reflux disease-associated heartburn, irrespective of the presence or absence of endoscopic oesophagitis. Aliment Pharmacol Ther 1997;11:755-63.

2 Bardhan KD, Muller-Lissner S, Bigard MA, et al. Symptomatic gastro-oesophageal reflux disease: double blind controlled study of intermittent treatment with omeprazole or ranitidine. The European Study Group. BMJ 1999;318:502-7. 